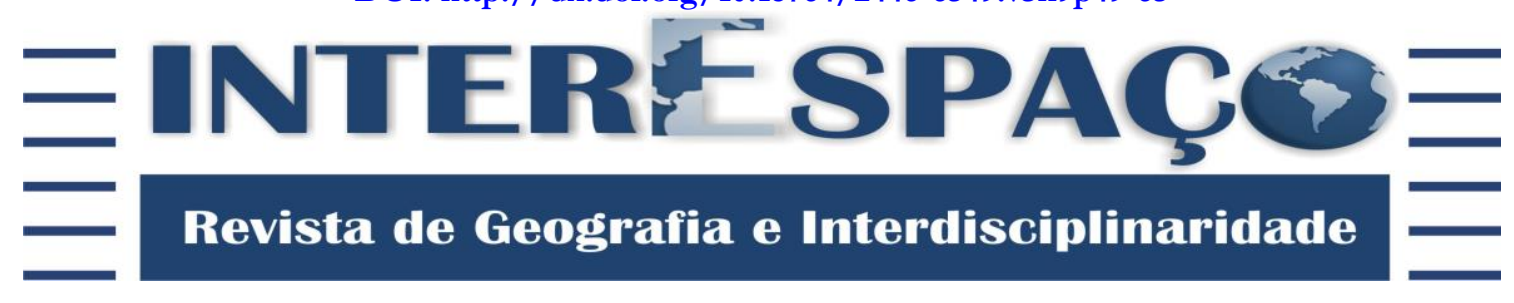

\title{
ESCRAVIDÃO CONTEMPORÂNEA: condições de trabalho no relato de maranhenses resgatados de trabalho escravo contemporâneo
}

\section{CONTEMPORARY SLAVERY: working conditions in the report of Maranhão rescued from contemporary slave labor}

\section{LA ESCLAVITUD CONTEMPORÁNEA: las condiciones de trabajo en la presentación de maranhenses rescatados de trabajo esclavo contemporáneo}

\section{Nilziane Costa Costa}

Estudante do Curso de Licenciatura em Ciências Humanas/História pela Universidade Federal do Maranhão - UFMA/Campus de Pinheiro.

nilzycosta@hotmail.com

\section{Sávio José Dias Rodrigues}

Doutor em Geografia pela Universidade Federal do Ceará - UFC. Professor Adjunto do Curso de Licenciatura em Estudos Africanos e Afro-Brasileiros da Universidade Federal do Maranhão -

$$
\text { UFMA. }
$$

saviodiasbr@hotmail.com

Recebido para avaliação em 28/01/2017; Aprovado para publicação em 20/03/2017.

\begin{abstract}
RESUMO
Analisar as condições de trabalho no relato dos trabalhadores vítimas de trabalho escravo contemporâneo como forma de identificar a precarização do trabalho e objetificação do ser humano nesse tipo de prática. Buscamos compreender as condições de trabalho e o perfil das vítimas que são aliciadas, fazendo uma relação entre condições socioeconômicas nas regiões de origem e as condições em que esses sujeitos se submetem. Este trabalho desenvolveu-se a partir de pesquisa bibliográfica, sobretudo, se embasando teoricamente na análise do materialismo histórico, além da coleta de dados na Comissão Pastoral da Terra, nos período de 2003 a 2014 e pesquisa de campo nos municípios de Açailândia, Santa Helena e Palmeirândia, bem como, relações com representações fílmicas brasileiras. As falas dos sujeitos aliciados para o trabalho escravo mostram condições que estão aquém da dignidade, apontando, por exemplo, a partilha de espaços e de água com animais como o gado das fazendas. Além dessas condições, as situações de medo impostas aos trabalhadores no momento da denúncia afetam a sua vida em diversos aspectos cotidianos, como do trabalho ou mesmo das relações sociais. Muitos dos aspectos psicológicos pós-aliciamento se vinculam com o trauma da condição vivida e o medo. A reprodução da pobreza no Maranhão tem sido um dos fatores para a saída de trabalhadores para outras regiões do país e seu aliciamento para o trabalho escravo. A necessidade e na busca por melhores condições de vida, trabalhadores aceitam qualquer oferta de trabalho e assim são alvos fáceis para aliciadores do trabalho escravo contemporâneo.
\end{abstract}

Palavras-chave: Trabalho Escravo; Condições de Trabalho; Maranhão.

ABSTRACT
To analyze the conditions of work in the report of the workers victims of contemporary slave labor
as a way of identifying the precariousness of work and objectification of the human being in this
type of practice. We seek to understand the working conditions and the profile of the victims that
are attracted, making a relation between socioeconomic conditions in the regions of origin and the 


\section{| Nilziane Costa Costa | Sávio José Dias Rodrigues |}

conditions in which these subjects submit. This work was developed from a bibliographical research, mainly based on the analysis of historical materialism, besides the data collection in the Pastoral Land Commission From 2003 to 2014 and field research in the municipalities of Açailândia, Santa Helena and Palmeirândia, as well as relations with Brazilian film representations. Speeches by people who are attracted to slave labor show conditions that fall short of dignity, such as the sharing of spaces and water with animals such as farm animals. In addition to these conditions, the situations of fear imposed on the workers at the time of denunciation affect their life in various everyday aspects, such as work or even social relations. Many of the post-gypsy psychological aspects are linked to the trauma of the lived condition and fear. The reproduction of poverty in Maranhão has been one of the factors for the exit of workers to other regions of the country and their enticement for slave labor. The necessity and the search for better living conditions, workers accept any job offer and thus are targets easy for enablers of contemporary slave labor.

Keywords: Slave Labor; Work Conditions; Maranhão.

\section{RESUMEN}

Analizar las condiciones de trabajo en la notificación de los trabajadores víctimas de la esclavitud contemporánea como una manera de identificar la precariedad del trabajo y la objetivación del ser humano en este tipo de práctica. Buscamos entender las condiciones de trabajo y el perfil de las víctimas que son atraídos por hacer una relación entre las condiciones socioeconómicas en las regiones de origen y las condiciones en que estos sujetos se someten. Este trabajo fue desarrollado a partir de la literatura, sobre todo si en teoría, basándose en el análisis del materialismo histórico, además de la recolección de datos en la Comisión Pastoral de la Tierra y de la investigación de campo en los municipios de Açailândia, Santa Elena y Palmeirândia. Los discursos de la gente engaña a los esclavos muestra condiciones de trabajo que están debajo de la dignidad, señalando, por ejemplo, compartiendo espacios y animales acuáticos como explotaciones de ganado vacuno. Además de estas condiciones, las situaciones de miedo impuestas a los trabajadores en el momento de la terminación afectan a su vida en muchos aspectos cotidianos, como el trabajo o las relaciones sociales. Muchos de los aspectos psicológicos post-aseo están vinculados a la condición de trauma experimentado y el miedo. La reproducción de la pobreza en Maranhão ha sido uno de los factores para la salida de los trabajadores a otras regiones del país y su arreglo personal para el trabajo esclavo. La necesidad y la búsqueda de mejores condiciones de vida, los trabajadores aceptan ninguna oferta de trabajo y por lo tanto son objetivos fáciles para los reclutadores del trabajo esclavo contemporáneo.

Palabras clave: El Trabajo Esclavo; Condiciones de Trabajo; Maranhão.

\section{INTRODUÇÃO}

Pretendemos neste trabalho analisar as condições de trabalho nos relatos de trabalhadores maranhenses resgatados ou aliciados para o trabalho escravo contemporâneo como maneira de identificar as formas de precarização do trabalho e a objetificação dos sujeitos nessa prática. Buscamos compreender as condições de trabalho e o perfil das vítimas que são aliciadas, fazendo uma relação entre condições socioeconômicas nas regiões de origem e as condições em que esses sujeitos se submetem. Entendemos, assim, que a análise do trabalho escravo contemporâneo se faz dentro do contexto de reprodução do modo de produção capitalista. 


\section{| Nilziane Costa Costa | Sávio José Dias Rodrigues |}

O modo de produção atual tem se abastecido de mão de obra escrava, reproduzindo condições de trabalho degradantes e que desumanizam o trabalhador. Sujeitos com sua liberdade limitada, trocados como mercadorias, tratados como animais. A mão de obra é apenas um objeto de troca para o modo de produção.

Decorridos mais de 120 anos da promulgação da lei que aboliu juridicamente a escravidão no Brasil, a Lei Áurea em 1888, ainda existem muitos trabalhadores em condição de escravidão ou em situações análogas a de escravo no Brasil. Esta prática ainda se reproduz em pleno século XXI, se apropriando de novas formas de coagir trabalhadores e com novas formas de operacionalização. Essa configuração é denominada de "trabalho escravo contemporâneo" e tem se reproduzido em todo o território brasileiro, em diversas atividades econômicas, desde aquelas desprovidas de usos tecnológicos, até àquelas com utilização de insumos técnicos de ponta.

O trabalho escravo contemporâneo é considerado crime e consta no Art. 149 do Código Penal Brasileiro dessa maneira:

Reduzir alguém a condição análoga à de escravo, quer submetendo-o a trabalhos forçados ou a jornada exaustiva, quer sujeitando-o a condições degradantes de trabalho, quer restringindo, por qualquer meio, sua locomoção em razão de dívida contraída com o empregador ou preposto (BRASIL, 2003).

O artigo supracitado ressalta alguns elementos para caracterizarem o trabalho escravo contemporâneo, tais como: trabalho forçado, jornada exaustiva, condição degradante e restrição de locomoção em razão de dívida. Esses elementos presentes nas relações de trabalho entre empregador e empregado são características que definem a situação do trabalho escravo contemporâneo.

O trabalho escravo contemporâneo no Brasil parece ser uma relação de exploração anacrônica na história do país e do desenvolvimento do modo de produção capitalista. Sua permanência é analisada por alguns autores como um resquício do atraso na modernidade. Isso dá a entender que é uma relação a ser ultrapassada pelo modo de produção. Esta forma de análise se faz presente em autores como José de Souza Martins e fica evidente quando ele argumenta em torno da permanência do que denomina de arcaico:

Esse tipo de conflito não é próprio de um Brasil moderno, mas de um Brasil arcaico. O buraco, porém, é um pouco mais embaixo: esse é o conflito do Brasil arcaico contra o Brasil moderno. E também o conflito que mostra de modo sangrento ações, no interior do próprio Estado, no sentido de amarrar e frear os propósitos modernizadores do governo: o que está em jogo é a viabilidade e a continuidade de sua política e, no limite, a sua própria continuidade (MARTINS, 1997, p. 55). 


\section{| Nilziane Costa Costa | Sávio José Dias Rodrigues |}

Essa perspectiva de contraditoriedade entre o arcaico e o moderno representa que o trabalho escravo é apenas uma forma anômala no modo de produção capitalista, uma forma que é exceção no funcionamento do sistema, apenas um resquício de outros modos de produção. Parece que esse raciocínio é bem conveniente para diversos setores da sociedade, sobretudo, os que encampam o projeto modernizador da economia brasileira. Afinal, esta é tida como antagônica dessas formas de exploração do trabalho.

Leonardo Sakamoto coloca que:

[...] O trabalho escravo contemporâneo não é simplesmente um resquício de práticas anacrônicas que sobrevivem dentro de um contexto moderno, mas uma reinvenção destas, a forma mais degradante de exploração da força de trabalho e negação de direitos que opera nos locais e momentos em que o modo de produção de expande (SAKAMOTO, 2011, p. 371).

Entendemos, dessa maneira, que o anacronismo apresentado é apenas aparente. $\mathrm{O}$ trabalho escravo também é parte da modernidade, como uma das formas que o modo de produção do capital se dinamiza e se organiza. A modernidade no capitalismo subordina outros modos de produção, possibilitando a expansão da acumulação de capital a partir da sobre-exploração do trabalho.

Esse artigo se insere nesse âmbito, de refletir o trabalho escravo contemporâneo como parte do modus operandi do capitalismo, ressaltando ele como integrante da lógica de precarização do trabalho e desumanizador da vida. Dessa maneira, entender a permanência do trabalho escravo na atualidade, bem como suas implicações na vida do trabalhador, com a precarização das condições de trabalho é importante.

Para esse artigo, utilizamos a metodologia da história oral, baseado nos estudos de Alberti (2005; 2000), buscando as falas dos sujeitos, sobretudo os resgatados de trabalho escravo contemporâneo. Também fizemos uma busca por bibliografia, além de coletas de dados e informações em instituições como a Comissão Pastoral da Terra (CPT), sindicatos de trabalhadores e trabalhadoras rurais, além de outras instituições e movimentos sociais. Os trabalhos de campo foram feitos nos municípios de Açailândia (oeste do Maranhão), Santa Helena e Palmeirândia (os dois são municípios da Baixada Maranhense), nos quais realizamos entrevistas com trabalhadores regatados de trabalho escravo contemporâneo. Foram realizadas três entrevistas coletivas, uma em cada município elencado, mais algumas entrevistas individuais. As entrevistas coletivas realizadas nos municípios de Santa Helena e Palmeirândia foram feitas a partir do projeto de extensão “Questão agrária, direitos humanos e prevenção ao trabalho escravo contemporâneo em comunidades rurais da baixada maranhense", com a realização de uma oficina em cada um dos dois municípios, 
onde participaram trabalhadores e trabalhadoras moradores da zona rural dos dois municípios. No caso do município de Santa Helena, realizamos entrevistas com mulheres que relataram ter vivenciado situação de exploração infantil, sobretudo na infância e adolescência.

Organizamos o trabalho em duas partes. A primeira trata da precarização do trabalho a partir do entendimento do trabalho escravo como uma forma extrema e contraditória que se reproduz no seio do modo de produção como parte da produção capitalista. $\mathrm{Na}$ segunda parte do artigo tratamos do perfil dos trabalhadores aliciados, percebendo elementos desse perfil como parte da vulnerabilidade para o trabalho escravo contemporâneo.

\section{A PRECARIZAÇÃO DO TRABALHADOR E A OBJETIFICAÇÃO DO SUJEITO}

O trabalho escravo contemporâneo se destaca pela degradação do trabalhador e violação dos direitos trabalhistas. Nesta situação, o trabalhador é transformado em mero objeto de trabalho. Sua mão de obra torna-se elemento para desenvolvimento de capital numa situação limite, em que, não somente a força de trabalho do sujeito vira mercadoria, mas sim, o próprio trabalhador, fazendo com que não somente a força de trabalho seja trocada, mas o próprio sujeito. A situação limite da alienação.

O significado da humanização do homem tem se dado, sobretudo, a partir de duas percepções: a primeira, o trabalho como categoria de transformação da natureza, em que Karl Marx faz uma inserção grande e que é remetida por outros teóricos contemporâneos. Ricardo Antunes sintetiza sua teoria assim: que é "em sua realização cotidiana, que o ser social se distingue de todas as formas pré-humanas" (ANTUNES, 2013, p. 07). Como condição do ser social enquanto tal, o trabalho transforma este e o seu entorno. David Harvey coloca que "não podemos transformar o que se passa ao nosso redor sem transformar a nós mesmos" (HARVEY, 2013, p. 114). A transformação da natureza/mundo é parte da transformação do próprio ser humano. A transformação presume a consciência da transformação (MARX, 2011).

Gyögy Lukács (2012, p. 286) coloca que este é o princípio ontológico de Marx. Em que "o trabalho dá lugar a uma dupla transformação. Por um lado, o próprio ser humano que trabalha é transformado por seu trabalho [...]". Do outro lado, "os objetos e as forças da natureza são transformados em meios de trabalho, em objetos de trabalho, em matériasprimas etc.”. É nessas condições que a transformação da natureza em segunda natureza que 


\section{| Nilziane Costa Costa | Sávio José Dias Rodrigues |}

faz do ser essencialmente Ser. Mas isso implica dizer que esse processo se dá mediante a consciência do ser que transforma e do produto criado.

Essa condição de desrealização do operário, como Konder (2009, p. 42) coloca, é a alienação do trabalhador em relação ao seu produto, "porque tal produto, antes mesmo da realização do trabalho, pertence a outrem que não é o trabalhador". Podemos acrescentar que não é só o produto do trabalho que antes mesmo de sua produção já tem um dono que não é o próprio sujeito que realiza trabalho e que "é levado a considerar o sistema de propriedade que promove a desapropriação do trabalhador em relação ao produto do trabalho". A própria força de trabalho do trabalhador já é apropriada pelo sistema de propriedades. Alargada, essa ideia pode nos levar a crer da própria posse do trabalhador pelo capitalista, como por anos foi imaginado a posse dos escravos por elites nacionais, principalmente as europeias. A não realização dos sujeitos por serem eles próprios a propriedade de outros sujeitos se torna parte da estrutura do modo de produção capitalista.

Essa situação-limite do processo de alienação aparece como constante e que rompe barreiras da legalidade ou da moralidade fundada em cada época do modo de produção capitalista, reproduzindo-se de maneira natural. Podemos dizer que o processo de alienação do sujeito se dá também pela apropriação do seu trabalho a partir do cerceamento da sua liberdade e espoliação da sua força de trabalho. Essa espoliação se dá ao mesmo tempo em que impõe ao sujeito condições de trabalho e de vida semelhante às oferecidas aos animais de abate, sujeitando-os à condição de propriedades, de objetos a serem trabalhados e transformados pela propriedade exercida por seus senhores, seja os antigos senhores de escravo que viviam na "Casa Grande"1, seja os novos latifundiários escravagistas ou industriais/capitalistas que mantém mão de obra escrava em suas produções.

$\mathrm{Na}$ verdade, essa condição remete à própria desumanização do ser humano a partir da separação por completo de sua força de trabalho que lhe é totalmente alienada ou ainda da apropriação desta pelo capitalista como sendo a apropriação de um produto.

O trabalho escravo é a degradação do humano em propriedad ${ }^{2}$, a sua transformação em objeto, sendo assim, passível da conveniência do seu senhor. Uma das conveniências é o não investimento de capital no próprio pagamento de salários.

\footnotetext{
${ }^{1}$ Refere-se ao nome da residência do senhor de terras e escravagista. A casa-galpão que residiam os escravos era denominada de Senzala.

2 O filme Amistad, de 1997, dirigido por Steven Spielber, expressa bem essa relação de propriedade. No filme, em 1839, dezenas de africanos escravizados vão a julgamento pelo assassinato da tripulação de um navio de nome Amistad, porém, o comandante da marinha americana responsável por prender as pessoas escravizadas, os supostos donos deles e a rainha espanhola passam a requerer suas posses. A defesa que os abolicionistas passam a empenhar no caso, se afasta em querer trazer a imoralidade da propriedade de pessoas
} 


\section{| Nilziane Costa Costa | Sávio José Dias Rodrigues |}

A utilização de trabalho escravo no capitalismo pode ser vislumbrada como instrumento competitivo. Assim, a fala de José Damião de Lima Trindade (2011, p. 27) "para o capital manter-se à tona na concorrência, vale até a restauração de relações de trabalho análogas ao trabalho escravo", ficando evidente que a preocupação gira em torno da manutenção do capital e que os trabalhadores se tornam meros instrumentos nesse processo, secundarizados e até descartáveis no ciclo do capital.

Quando nos remetemos ao termo trabalho escravo, a imagem que logo relacionamos tem a ver com a violência física e o aprisionamento, geralmente em grilhões, formas de objetificação do trabalhador comuns no período escravagista colonial e imperial brasileiro. Atualmente, o trabalho escravo tem forte alicerce nas situações de pobreza a que são levados os trabalhadores. Então, isso faz com que o trabalho escravo contemporâneo tenha outras marcas, como por exemplo, a escravização por dívida. A dívida contraída pelo trabalhador, muitas vezes no momento da saída do seu lugar de origem, capitaneado por gatos para migrarem para outras regiões, quando, ao chegarem, descobrem as dívidas que são obrigadas a pagar. Assim, a exploração não se baseia mais no estatuto legal da escravidão dos períodos de colonização e de período imperial, ela, apesar de ilegal, é parte da reprodução de atividades econômicas, seja no campo como na cidade, em que há a coerção do trabalhador utilizando dívida, uso de força na retenção de sua liberdade, a imposição de trabalho degradante. Assim, não somente a dívida, mas também elementos de coerção do trabalhador, que vão da violência física, até a moral e psicológica. É como a Neide Esterci (2008, p. 28), citando Whittaker (1991), destaca que “os escravos de hoje não são amarrados por correntes de ferro, mas por dívida e exploração”. Entende-se, assim, que o trabalhador se torna escravo do próprio trabalho e de sua necessidade pela sobrevivência.

As condições socioeconômicas nas regiões de origem dos trabalhadores migrantes resgatados de trabalho escravo contemporâneo podem ser trazidas aqui como um fatorchave que se relaciona com o aliciamento. A pobreza e a busca por condições de sobrevivência podem ser elencadas como elementos importantes para entendermos o porquê os trabalhadores se submeterem a quaisquer tipos de trabalho e condições.

As condições de trabalho degradantes são uma das características principais do trabalho escravo. Lugares de acomodação dos trabalhadores insalubres, ausência de banheiros, camas, até mesmo usos compartilhados com animais. As falas dos sujeitos aliciados para o trabalho escravo contemporâneo mostram condições que estão aquém da

por outras pessoas e começa a tratar de direito comercial. Essa transição nos argumentos da defesa exprime a moral do período que o filme retrata. 


\section{| Nilziane Costa Costa | Sávio José Dias Rodrigues |}

dignidade, apontando, por exemplo, a partilha de espaços e de água com animais das fazendas. A fala de um dos trabalhadores entrevistados ${ }^{3}$ descreve bem essa situação descrita acima:

Ah! O alojamento lá era barraco mesmo de palha com uma lona. Quando vinha a chuva, aí tinha que levantar da rede pra erguer, pra passar a tempestade de chuva senão molhava todo mundo. Assim que era, chiqueiro de porco apregado no barraco lá era nojento lá [...]. (Informante 1, Entrevista concedida em: 13/05/2015).

Esse relato de um dos trabalhadores em uma fazenda do município de AçailândiaMA é uma descrição do ambiente de trabalho, bem como do alojamento em que ele vivia. O uso de espaços de quaisquer espécies para acomodação de mão de obra é comum. É evidente, nesses casos, a desumanização dos trabalhadores. Sua descartabilidade é mostrada também quando o mesmo informante fala sobre a alimentação: “A comida era arroz com feijão, tinha carne quando alguém ia pra mata e matava às vezes um tatu, uma paca, se arriscando, que onça tinha demais lá. Tỉnha não, tem! Hoje ainda não se acabou, assim que era" (Informante 1, Entrevista concedida em: 13/05/2015). Caso estes quisessem complementar a refeição tinham que arriscar suas vidas na mata para pegar alguma caça. Esse é apenas um dentre muitos relatos de trabalhadores que passam por essa situação. Por muitas vezes essas falas se repetem nas entrevistas, demonstrando que não é apenas um caso isolado das situações de trabalho escravo.

A subordinação dos trabalhadores a condições desumanas, aquém da dignidade, vivendo em um barraco de palha coberto apenas por uma lona e uma alimentação composta apenas por arroz e feijão, faz-nos crer que o trabalho escravo é, ele próprio, uma relação limite da alienação do trabalhador.

$\mathrm{Na}$ mesma perspectiva, outro trabalhador, este do município de Pindaré-MA, descreve seu ambiente de trabalho:

[...] nós ficava era debaixo do pé de cajueiro [...] o barraco velho de lona [...], (a comida) era só feijão e arroz. Tinha um bocado de galinha lá, ovo, galinha pusia lá, mas num deixavam o cabra cumer um ovo, porco tinha muito, mas num matava [...] (Informante 2, Entrevista concedida em: 13/05/2015).

\footnotetext{
3 As entrevistas foram concedidas por trabalhadores resgatados de trabalho escravo contemporâneo, no I Encontro Inter-Regional de Trabalhadores/as Resgatados/as do Trabalho Escravo Contemporâneo, realizado pelo Centro de Defesa da Vida e dos Direitos Humanos Carmen Bascarán, em Açailândia, no ano de 2015.
} 


\section{| Nilziane Costa Costa | Sávio José Dias Rodrigues |}

Percebe-se nesses dois relatos que a precariedade do trabalho é a mesma e que compartilham de uma mesma situação no que diz respeito ao alojamento e à alimentação. A produção dos estabelecimentos chega a ser mais importante do que os próprios trabalhadores. Tornam-se objetos com menor valor do que as mercadorias que produzem.

Essas situações são exemplos claros de violações às leis trabalhistas e ao código penal brasileiro, circunstâncias estas que ferem a dignidade do trabalhador, com condições de trabalho insalubres e de alojamento e alimentação incompatíveis com a dignidade humana.

Geralmente, o trabalho escravo contemporâneo acontece com sujeitos migrantes. O fator geográfico é um elemento importante, pois garante que o trabalhador não consiga contato com sua família.

A saída do trabalhador do seu local de origem acontece sobre diversas situações. Algumas são traços de condições de vida já precárias e que indicam uma possibilidade de subordinação muito maior. O primeiro relato informa o porquê o trabalhador saiu de seu local de residência:

[...] porque sou analfabeto [...] hoje em dia, quem tem saber, ainda tão roçando juquira ${ }^{4}$, sem emprego e eu fui porque eu não sei nadinha.

[...] Buscar o dinheiro, a condição (Informante 2, Entrevista concedida em: $13 / 05 / 2015)$.

Essa primeira fala apresenta de maneira direta a condição econômica e seu alicerce em torno dos estudos, da renda e do acesso ao mercado de trabalho do sujeito entrevistado. Ela também expressa a situação de naturalização da exploração e que é diretamente relacionada aos estudos, ou seja, quanto menor a quantidade de tempo de estudo, maior será a exploração e pior a condição de trabalho. Podemos perceber que essa é uma relação que se faz cotidianamente e a construção na mentalidade da elite brasileira que ainda lhe confere características escravocratas.

A relação que a classe proprietária manteve com os trabalhadores reproduziu a maior exploração possível, como afirma Tânia Bacelar Araújo (2000). Para essa autora, a sociedade brasileira tem três características principais. A primeira é o não acesso aos meios de produção, que é histórico na formação brasileira, e o acesso à terra é uma evidência

\footnotetext{
${ }^{4} \mathrm{O}$ termo juquira é uma designação muito utilizada pelos trabalhadores para explicar o serviço de corte do mato, um trabalhador explica que "a juquira é praticamente um mato que já foi é quebrado [...], então praticamente um mato que já foi desmatado [...], então esse outro que vem é que se chama da juquira, o que a gente roça com uma foice $[. .]$.$" .$
} 


\section{| Nilziane Costa Costa | Sávio José Dias Rodrigues |}

principal. A segunda característica diz respeito ao caráter contraditório da economia brasileira, em que, de um lado, produz com tecnologia de ponta e, do outro, reproduz índices de desigualdade muito altos. O terceiro elemento característico é a manutenção de uma alta taxa de exploração do trabalhador, sendo que ela exemplifica esse último fato numa rápida comparação de salários entre trabalhadores do mesmo ramo na Europa e no Brasil, no qual o recepcionista de um hotel 4 estrelas na Europa receberia quatro vezes mais do que um trabalhador ocupante do mesmo posto no Brasil.

Essa última característica tem uma relação intrínseca com a mentalidade da elite brasileira, de exploração do trabalhador aos moldes da escravidão colonial. O trabalhador limitado de direitos, sem perspectivas e numa hierarquia social perversa é percebido como subalterno em todas as esferas, desde a pública até o círculo privado. Um exemplo é a posição subalterna dos trabalhadores rurais brasileiros que não foram totalmente abrangidos pela Consolidação das Leis Trabalhistas (CLT) e nem as trabalhadoras domésticas. Podemos falar que essa última categoria herdou características da escravidão colonial e imperial brasileira, tendo as trabalhadoras domésticas que lidar com situações que frequentemente se assemelham à escravidão, como as situações descritas no filme de Anna Muylaert, de 2015, “Que horas ela volta?”, no qual a personagem interpretada por Regina Casé trabalha como empregada doméstica, vivendo integralmente na casa dos seus patrões. Sua filha, quando vai prestar vestibular na cidade de São Paulo, fica na casa dos patrões de sua mãe, gerando uma série de conflitos com a família de classe média que lhe recebe. A adolescente promove uma série de rupturas em relação aos códigos de postura criados entre patrões e empregada, os quais se assemelham à manutenção da empregada/escrava em uma nova casa grande. No mesmo sentido, filmes como "Quanto vale ou é por quilo?" do diretor Sérgio Bianchi, lançado no ano de 2005, também retrata a analogia possível entre o trabalho das empregadas domésticas e o trabalho escravo, dentre outros debates sobre pobreza e filantropia.

Para essas duas categorias de trabalhadores e trabalhadoras, tanto de trabalhadores rurais como de trabalhadoras domésticas, foram necessárias legislações específicas para garantir direitos que, em tese, a CLT dava à universalidade de trabalhadores. Respectivamente, a lei $\mathrm{n}^{\circ}$ 4.214/1963 que institui o "Estatuto do Trabalhador Rural" e a Proposta de Emenda Constitucional no 66 (promulgada em 2 de Abril de 2013), a chamada PEC das Domésticas, que assegura direitos como salário mínimo, férias proporcionais, horas extras, adicional noturno e o Fundo de Garantia por Tempo de Serviço (FGTS). 


\title{
| Nilziane Costa Costa | Sávio José Dias Rodrigues |
}

A Casa Grande se reproduziu no país com novos rótulos, mas, agora, socialmente ajustada e adaptada para ser aceita pela moral contemporânea, sem que necessariamente o domínio e o poder do patrão excluam a égide da relação entre escravagistas e escravos, ou seja, a propriedade como fundamento dessa relação, em que o senhor de escravos mantém sua posse de maneira escancarada.

Outro relato de trabalhador resgatado diz assim:

\begin{abstract}
A minha mãe é pobre, ela não tem o que me dá, meu pai quando separou da minha mãe nós era quase todo mundo de menor lá em casa, aí eu parei de estudar e ganhei o mundo, comecei a andar. (Informante 1, Entrevista concedida em: 13/05/2015).
\end{abstract}

Uma situação de pobreza que é intergeracional, que passa de pai pra filho, mostrando a dificuldade de ascensão social que as famílias enfrentam. Na verdade, essa é parte da naturalização da exploração do sujeito como parte da vida dele, basta ter pais pobres. Parece que os relatos indicam uma situação genética, que passa de geração para geração. Na verdade, não é uma relação biológica que coloca esses sujeitos em situação subalterna. As condições de acesso à terra tem íntima relação com a família, assim como com a escola, cultura, etc. Dessa maneira, por exemplo, não se admira que a condição de sem-terra seja vivida pelos pais e pelos filhos. Óbvio, que temos situações também antagônicas, como no caso explicitado no filme "Cabra Marcado para Morrer”, de 1984, de Eduardo Coutinho. No filme, a Elizabeth Teixeira, uma das pessoas retratadas no filme/documentário, segue com o seu falecido marido na condição de sem-terra, porém, seu pai no período retratado pela película era um dono de sítio que, inclusive, arrendava suas terras para João Teixeira, esposo de Elizabeth.

Um elemento importante nos relatos tem sido como os trabalhadores colocam a alfabetização como uma das condições para conseguir emprego. Assim, eles deixam perceber que, o fato de o sujeito não ser alfabetizado, lhe conduz naturalmente a um emprego precário. Portanto, o fator "qualificação" é colocado como influenciador (ou não) para a submissão de trabalhadores nesta prática.

Podemos sintetizar a submissão do trabalhador a condições precárias de emprego, como o fazem Vieira e Bruno (2011, p. 39):

Os trabalhadores que se encontram em situação de trabalho escravo são movidos pela necessidade premente para aceitar ofertas de emprego, tendo em vista sua posição desfavorável no mercado de trabalho - baixa qualificação, baixa escolaridade $[\ldots]$. 
O complemento de Vieira e Bruno (2011, p. 39), no que diz respeito ao motivo pelo qual trabalhadores se submetem a determinadas situações devido "a pressão que sofrem face às necessidades da família, nas quais são, muitas vezes, os únicos responsáveis pelo sustento", se encaixa na fala do segundo trabalhador que por questões familiares teve que parar os estudos "e ganhar o mundo".

Desta forma, não somente questões socioeconômicas, como também questões familiares, influenciam a saída desses trabalhadores em busca de melhores condições de vida e sua necessidade premente os faz aceitar qualquer tipo de emprego.

\section{ENTRE RELATOS E O PERFIL DAS VÍTIMAS DE TRABALHO ESCRAVO}

O Estado do Maranhão é um "ambiente de miséria e fome", como é descrito por Ricardo Resende (2000, p. 35), quando destaca o ambiente em que se dá a contratação de trabalhadores para o trabalho escravo contemporâneo, destacando o nordeste e principalmente o estado do Maranhão. E é neste contexto de pobreza e fome que o trabalho escravo se reproduz. Na verdade, melhor dizendo, é a partir dele que essa prática se reproduz.

Os dados da Comissão Pastoral da Terra (CPT) mostram que o Maranhão foi um dos maiores exportadores de mão de obra aliciada para o trabalho escravo contemporâneo, conforme gráfico a seguir:

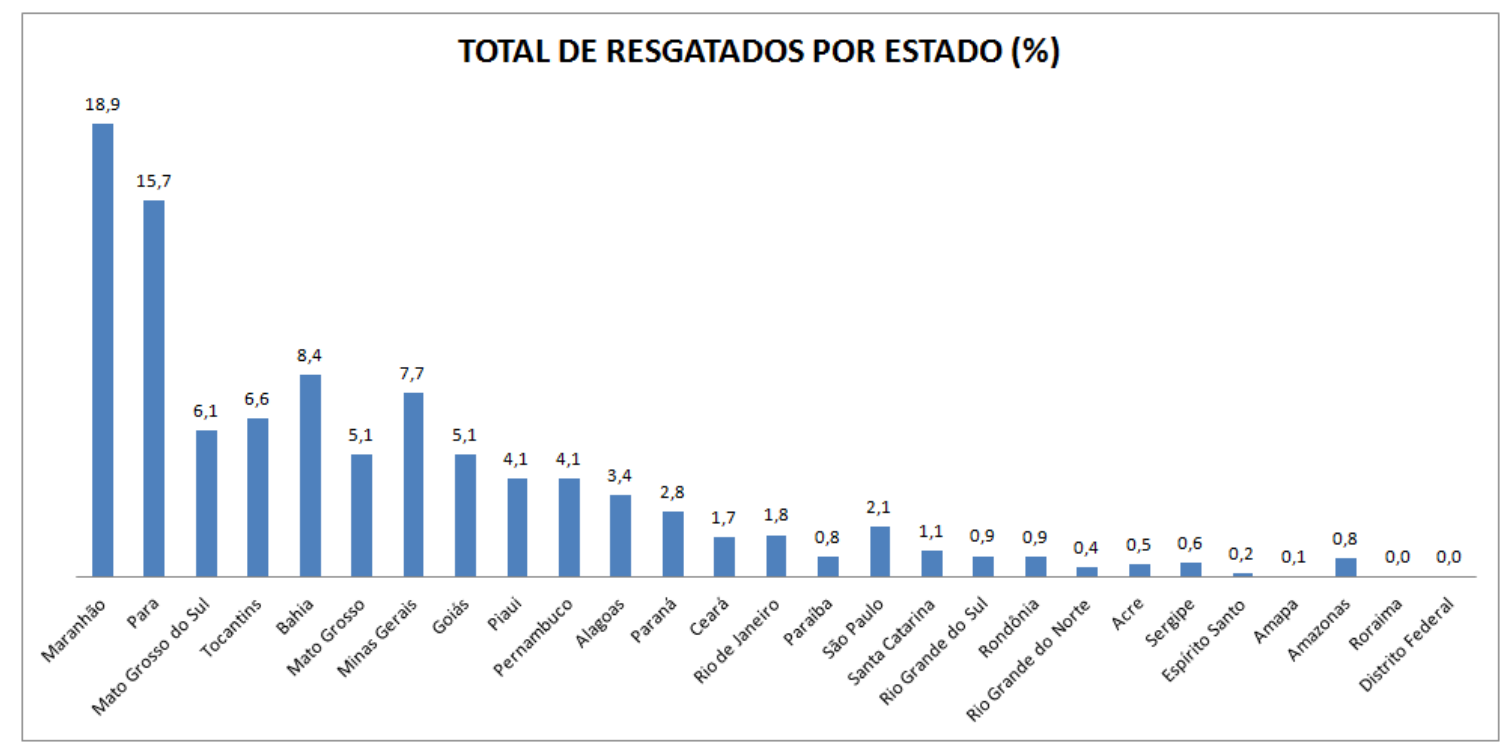

Gráfico 1 - Total de resgatados por estado de 2003 a $2014(\%)$

Fonte: CPT - Síntese estatística (2014). 
O estado do Maranhão aparece com quase 19\% de resgatados de trabalho escravo contemporâneo no Brasil. Isso quer dizer que, de cada 100 pessoas libertadas dessa situação, quase 19 eram maranhenses, quase 1/5 dos resgatados. O número relativamente grande vem, sobretudo, das condições de acesso aos meios de produção no estado, das condições de subsistência ou mesmo dos inúmeros minifúndios no estado.

Embora a situação fundiária no estado aponte para uma diminuição do número de minifúndios, ainda, o número destes imóveis rurais tem permanecido com uma quantidade considerável, conforme gráfico a seguir:

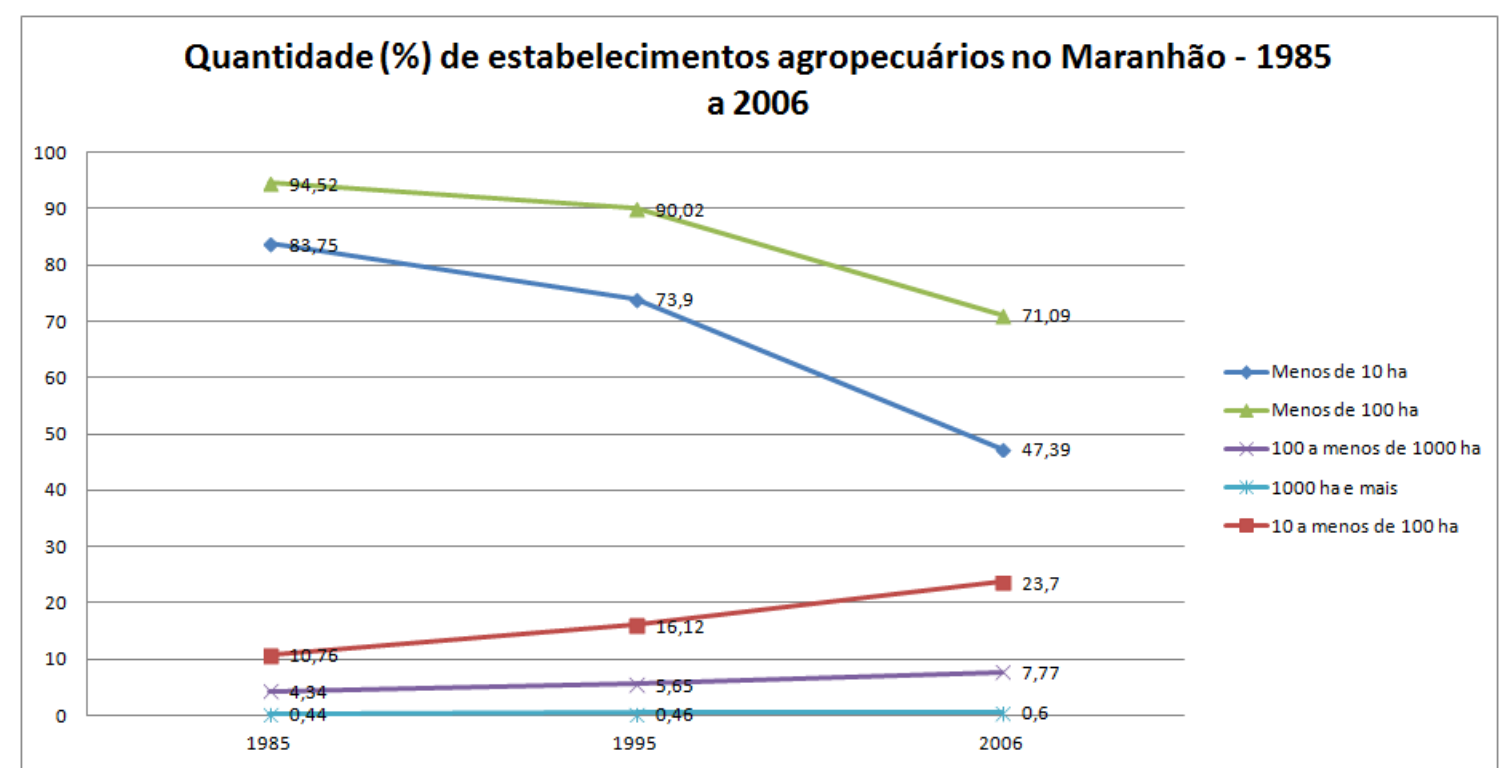

Gráfico 2 - Quantidade (\%) de estabelecimentos agropecuários no Maranhão - 1985 a 2006 Fonte: IBGE - Censo agropecuário 1985, 1995, 2006.

No período de 1985 a 2006 houve uma diminuição do número relativo de estabelecimentos com menos de 10 hectares (ha), indicando a redução do número de minifúndios e pequenas propriedades no Maranhão nesse período. Em compensação, aumentou-se o número de estabelecimentos entre 10 e 100 ha, mas, sobretudo, do número relativo de estabelecimentos entre 100 a 1000 ha e maiores que 1000 ha, demonstrando a concentração de terras no estado e também, a título de especulação, podemos associá-lo ao avanço do agronegócio em determinadas regiões do estado nesse intervalo de tempo.

A concentração de terras está diretamente ligada à pobreza, caracterizada pelo acesso restrito à terra nas áreas rurais do estado, principalmente, como fica explícito nos dados do IBGE. A reprodução da pobreza no Maranhão tem sido um dos fatores para a saída de trabalhadores para outras regiões do país e seu aliciamento para o trabalho escravo. A necessidade e a busca por melhores condições de vida têm feito trabalhadores migrantes aceitarem qualquer oferta de trabalho e assim são alvos fáceis para aliciadores do 


\section{| Nilziane Costa Costa | Sávio José Dias Rodrigues |}

trabalho escravo contemporâneo. Nesse ambiente de pobreza vivido pelo trabalhador, em que, geralmente, seus municípios de origem não oferecem oportunidades de emprego e de renda, os sujeitos não têm acesso aos recursos naturais, como por exemplo, a terra, a opção adotada pelos trabalhadores é a de se movimentar pelas regiões do país em busca de uma colocação no mercado de trabalho.

A fala a seguir mostra a colocação de um dos trabalhadores no que correspondem às oportunidades de trabalho em seu município de origem e a questão da migração:

[...] não, pra lá não tem assim não [trabalho], por isso que eles saem assim [...] pro mundo [...] por que pra lá não tem juquira assim pro cara ta roçando não, o cara faz mais lá é pescar, pescaria assim por causa que o rio passa bem no meio e, quem tem os materialzinho de rede de pesca e, quem não tem, o jeito é cair na juquira moço, roçar (Informante 2, Entrevista concedida em: 13/05/2015).

Assim, o município de origem não oferece oportunidade de trabalho, nem mesmo o de "juquira", como é descrito pelo trabalhador, o que dificulta ainda mais sua permanência.

A falta de empregos e de estudo pode estar relacionada à vulnerabilidade dos trabalhadores pobres que migram e acabam sendo vítimas do trabalho escravo contemporâneo. Quando questionados sobre o porquê foram escravizados, os relatos se centraram no fato de eles não terem estudo e na sua necessidade financeira. Um primeiro relato afirma assim:

Logo porque eu não tive estudo, né?, isso que eu tenho a dizer eu não tive estudo e eu tive que encarar as consequências, né?! (Informante 1, Entrevista concedida em: 13/05/2015).

De maneira naturalizada, a exploração do trabalho aparece como parte de um estrato social hierarquizado a partir das oportunidades alcançadas e que têm no estudo um dos seus elementos. Em outras palavras, quem não teve acesso aos estudos tem que, naturalmente, arcar com as piores formas de trabalho, tendo que aguentar qualquer tipo de exploração. Um segundo relato colabora com essa ideia:

\footnotetext{
$\mathrm{Ah}$, isso aconteceu porque acho que sou analfabeto; não tenho leitura de nada mermo, serviço tem que fazer assim mermo, não tem outro jeito (Informante 2, Entrevista concedida em: 13/05/2015).
}

Na mesma linha da naturalização da subordinação e da hierarquia social, o terceiro relato apresenta a estratificação dos detentores de condições financeiras, assim ele expressa: 
Muito fácil, essa aí é mais fácil, por que quem não tem é escravo de quem tem (Informante 3, Entrevista concedida em: 13/05/2015).

E esse raciocínio se reproduz também na fala do informante 2:

Porque, aconteceu que, falta de condição financeira, né?, falta de condição financeira e a gente acreditando que ia trabalhar, melhorar mais a situação da gente (Informante 2, Entrevista concedida em: 13/05/2015).

Fica evidente que, para os trabalhadores, a questão do estudo seguida das condições socioeconômicas é um fator central e explicativo destes terem sido vítimas de aliciadores. Por serem pobres, analfabetos e sem estudo são "obrigados" a se submeterem a quaisquer que sejam as condições de trabalho impostas pelos empregadores, se submeterem a trabalhos degradantes, a alojamentos precários e má alimentação. Todas essas situações são naturalizadas por eles, sendo algo "normal" devido as suas condições e oportunidades que não tiveram. Assim, a situação em seus locais de origem influencia a migração para outros locais, onde as oportunidades aparentam "melhores" e suas condições sociais e econômicas os deixam vulneráveis, tornando-os alvos fáceis de aliciadores e os levando a aceitar qualquer oferta de trabalho.

No que se refere à vulnerabilidade, Ricardo Rezende Figueira (2000) coloca que "os trabalhadores tornaram-se vítimas porque já eram vítimas na situação econômica e social, vítimas por desconhecerem a lei; pelo baixo nível de escolaridade ou ausência de escolaridade; por não saberem dos riscos de serem submetidos ao trabalho forçado".

O número de trabalhadores maranhenses que se deslocam para outros lugares em busca de colocação no mercado de trabalho tem sido grande. O problema que circunda essa questão é que estes saem de seus locais de origem e acabam sendo aliciados para as formas contemporâneas de trabalho escravo, vivendo em condições de vida precárias, com má remuneração e muitas vezes sofrendo violência física.

\section{CONSIDERAÇÕES FINAIS}

A trajetória de vida dos sujeitos diz muito sobre a situação atual dos mesmos, trabalhadores oriundos de zona rural, sem acesso a recurso natural como a terra, muitas vezes sem escolaridade e faltam oportunidades em seus municípios de origem são as principais vítimas dos aliciadores para o trabalho escravo contemporâneo.

O Maranhão apresenta um cenário onde a pobreza se reproduz, possibilitando que haja a escravização de muitos trabalhadores devido à falta de oportunidades que o estado 
| Escravidão contemporânea: condições de trabalho no relato de maranhenses resgatados de trabalho escravo contemporâneo|

| Nilziane Costa Costa | Sávio José Dias Rodrigues |

não possibilita. A migração de trabalhadores possibilita na maioria das vezes a reprodução da mão de obra escrava, visto que os trabalhadores que saem vão em busca de melhores chances de emprego e, movidos pela necessidade premente, acabam aceitando qualquer oferta, seja degradante, forçado ou exaustivo, caracterizando assim o trabalho escravo contemporâneo.

As falas dos trabalhadores que foram resgatados ou aliciados para o trabalho escravo mostram o quão degradante é o trabalho desses sujeitos, o quão precária são as suas situações. Evidenciam ainda a situação na qual estes se encontram em suas regiões de origem, sem acesso a mercados de trabalho, a recursos naturais como a terra. Dessa forma, monta-se o perfil dos escravizados, trabalhadores oriundos da zona rural, muitas vezes sem estudo, sem qualificação, sem oportunidades. Assim, o trabalho escravo continua se reproduzindo e recrutando trabalhadores em situações de vulnerabilidade.

\section{REFERÊNCIAS}

ARAÚJO, Tânia Bacelar de. Ensaios sobre o desenvolvimento brasileiro: heranças e urgências. Rio de Janeiro: Revan Fase, 2000.

BRASIL. Decreto Lei $\mathbf{N}^{\circ} \mathbf{1 0 . 8 0 3}$, de 11 de Dezembro de 2003. Disponível em: < http://www.planalto.gov.br/ccivil 03/leis/2003/110.803.htm >. Acesso em: 09 abr. 2015.

ESTERCI, Neide. Escravos da desigualdade: um estudo dobre o uso repressivo da força de trabalho hoje. Rio de Janeiro: Centro Edelstein de Pesquisas Sociais, 2008.

FIGUEIRA, Ricardo Rezende. Por que o trabalho escravo? Estudos Avançados, Instituto de Estudos Avançados da Universidade de São Paulo, v. 14, n. 38, p. 31-50, jan./abr. 2000.

ANTUNES, Ricardo (Org.). A Dialética do Trabalho: escritos de Marx e Engels. São Paulo: Expressão Popular, 2013. v. 1.

HARVEY, David. Para entender o Capital. Livro 1. São Paulo: Boitempo, 2011.

Informante 1, Entrevista concedida a Sávio José Dias Rodrigues e Nilziane Costa Costa. Açailândia, 13/05/2015.

Informante 2 Entrevista concedida a Sávio José Dias Rodrigues e Nilziane Costa Costa, Açailândia, 13/05/2015.

Informante 3, Entrevista concedida a Sávio José Dias Rodrigues e Nilziane Costa Costa, Açailândia, 13/05/2015.

KONDER, Leandro. Marxismo e Alienação: contribuição para um estudo do conceito marxista de alienação. 2. ed. São Paulo: Expressão Popular, 2009. 
LUKÁCS, György. Para uma ontologia do ser Social I. Tradução: Carlos Nelson Coutinho, Mario Duayer e Nélio Schneider. São Paulo: Boitempo, 2012.

MARTINS, José de Souza. Fronteira: a degradação do Outro nos confins do humano. São Paulo: HUCITEC, 1997.

MARX, Karl. O Capital: crítica da economia política: livro I; 28. ed. Rio de Janeiro: Civilização Brasileira, 2011. v. 1.

SAKAMOTO, Leonardo. Os acionistas da casa grande: a reinvenção capitalista do trabalho escravo no Brasil contemporâneo. In: FIGUEIRA, Ricardo Rezende; PRADO, Adonia Antunes (Org.). Olhares sobre a escravidão contemporânea: novas contribuições críticas. Cuiabá: EdUFMT, 2011. p. 391-426.

TRINDADE, José Damião de Lima. Representações de trabalhadores, gatos e empregadores sobre o trabalho escravo. In: FIGUEIRA, Ricardo Rezende; PRADO, Adonia Antunes (Org.). Olhares sobre a escravidão contemporânea: novas contribuições críticas. Cuiabá: EdUFMT, 2011. p. 23-36.

VIEIRA, Maria Antonieta; BRUNO, Regina. Representações de trabalhadores, gatos e empregadores sobre o trabalho escravo. In: FIGUEIRA, Ricardo Rezende; PRADO, Adonia Antunes (Org.). Olhares sobre a escravidão contemporânea: novas contribuições críticas. Cuiabá: EdUFMT, 2011. p. 37-56. 